\title{
Consumer sensory evaluation and chemical composition of beef gluteus medius and triceps brachii steaks from cattle finished on forage or concentrate diets 1
}

\author{
A. Chail, * J. F. Legako, $\dagger^{2}$ L. R. Pitcher, $\neq$ R. E. Ward,* S. Martini, * and J. W. MacAdam \\ *Department of Nutrition, Dietetics, \& Food Sciences, Utah State \\ University, Logan, UT 84322; † Department of Animal \& Food Sciences, Texas Tech University, \\ Lubbock 79409; and †̣Department of Plants, Soils, \& Climate, Utah State University, Logan, UT 84322
}

\begin{abstract}
The objective of this study was to assess the impact of cattle finishing diet and muscle type on meat quality. Consumer sensory response, proximate composition, Warner-Bratzler shear force (WBSF), fatty acid composition, and volatile compounds were assessed from the gluteus medius (GM) and triceps brachii (TB) muscles of cattle ( $n=6$ per diet) which were grain-finished (USUGrain) on conventional feedlot or 2 forage diets, a perennial legume, birdsfoot trefoil-finished (USUBFT; Lotus corniculatus), and grass-finished (USUGrass; Bromus riparius). Diet had an interacting effect with muscle for all sensory attributes $(P \leq 0.002)$, except aroma and flavor $(P \geq 0.078)$. In forage-finished beef, tenderness, fattiness, overall liking, and WBSF tenderness of GM was greater $(P<0.05)$ than TB, whereas for USUGrain, the tenderness, fattiness, overall liking, and WBSF tenderness of both muscles were similar $(P>0.05)$ but the juiciness of TB was more liked than USUGrain GM $(P<0.05)$. The juiciness of foragefinished beef did not differ $(P>0.05)$ between GM and TB. Lower $(P<0.05)$ intramuscular fat (IMF) percent was determined for USUGrass beef in comparison with USUGrain beef. The IMF percent of USUBFT beef was similar $(P>0.05)$ to both USUGrass and USUGrain
\end{abstract}

beef. However, IMF percent was not impacted by muscle type $(P=0.092)$. The ratio of $n-6: n-3$ fatty acids was affected by muscle dependent on diet $(P=0.016)$. The ratio of $n-6: n-3$ fatty acids was affected by the interaction of muscle $\times \operatorname{diet}(P=0.016)$. Between forage diets (USUGrass and USUBFT), $n-6: n-3$ ratios were similar $(P>0.05)$ between GM and TB, whereas within USUGrain, the GM was greater $(P<0.05)$ than the TB. Cumulative MUFA was greater $(P<0.05)$ in USUGrain compared with both USUGrass and USUBFT, which were similar $(P>0.05)$. Strecker aldehydes, ketones, pyrazines, and methional were affected $(P \leq 0.036)$ by muscle and found to have a greater concentration in GM compared with TB. Overall, consumers determined that USUGrain GM and TB had similar $(P>0.05)$ quality ratings. However, within forage-finished beef, the GM was perceived more frequently $(P<0.05)$ to be of premium quality and the forage-finished TB was more frequently $(P<0.05)$ rated as having unsatisfactory quality. These findings were in agreement with ratings of tenderness and overall liking. Therefore, in the context of our consumer group grilled GM and TB steaks, grain-finished beef provided more uniform quality and eating experience compared with forage-finished beef.

Key words: beef, birdsfoot trefoil, fatty acids, grass finished, legumes, volatile compounds

\section{INTRODUCTION}

To increase availability and demand for beef, the beef industry has made an effort to use muscles from throughout the beef carcass (Philip, 2011). Several reports indicate beef muscles differ in palatability (Meisinger et al., 2006; Stetzer et al., 2008; Hunt et al., 2014; Legako et al., 2015). Previously, when the palatability of multiple beef muscles was surveyed, the gluteus medius (GM) and triceps brachii (TB) 
were ranked similarly for beef-flavor intensity, tenderness, and juiciness (Carmack et al., 1995). In a more recent survey of beef muscles, the TB was rated as having more overall tenderness and Warner-Bratzler shear force (WBSF) tenderness compared with the GM. However, the TB and GM had similar ratings for juiciness, beef flavor intensity, and off-flavor intensity (Rhee et al., 2004). In a separate study, WBSF values for the TB and GM did not differ (Belew et al., 2003). More recently, the TB was determined to have greater overall tenderness, juiciness, beef flavor intensity, and offflavor intensity in comparison with the GM (King et al., 2009). In general, when palatability traits are surveyed among multiple muscles, as in Carmack et al. (1995), Belew et al. (2003), and Rhee et al. (2004), the TB and GM receive moderate ratings in comparison with highly palatable and lowly palatable muscles. Overall, this implies that the TB and GM are of intermediate eating quality within the entirety of the beef carcass.

Beef finishing diet is widely known to impact palatability, where grain finishing produces a more acceptable flavor compared with forage-finished beef (Larick et al., 1987; Melton, 1990; Corbin et al., 2015; O’Quinn et al., 2016). However, dietary factors, such as fatty acid composition, have increased interest in foragefinished beef. Forage-finished beef is generally lower in fat content and has lower ratios of $n-6: n-3$ fatty acids $(<4.0)$, which may reduce incidence of cardiovascular disease (Simopoulos, 2004). Recently, forage finishing with a perennial legume, birdsfoot trefoil, was revealed to produce rib eye steaks with favorable fatty acid ratios while also having palatability comparable to that of grain-finished beef (Chail et al., 2016). However, it is unclear how a forage-finishing diet may impact muscles beyond the generally very palatable longissimus thoracis of the rib eye. Therefore, the objective of this study was to determine the influence of finishing diet between beef muscles of intermediate eating quality, that is, the TB and GM, on consumer liking and chemical and physical measures of meat quality.

\section{MATERIALS AND METHODS}

\section{Animal Care and Use}

All animal procedures and protocols in this study were approved by the Utah State University (USU) Animal Care and Use committee (Institutional Animal Care and Use Committee number 1493.

\section{Cattle Finishing and Harvest}

All cattle production and harvest procedures are described in detail by Chail et al. (2016). In brief, 18
Angus steers were selected from the USU beef herd at weaning and fed a mixture of corn silage and alfalfa hay. For finishing, 6 steers were placed on tall fescue grass for $6 \mathrm{wk}$ and then moved onto meadow bromegrass (Bromus riparius Rehmann) until slaughter. Six steers were fed on birdsfoot trefoil (Lotus corniculatus) until slaughter, and the remaining 6 steers were feedlot finished in a single pen on a concentrate diet of high-starch cereal grain until slaughter. Cattle were not implanted with growth hormones or treated with other growth-stimulating inputs. Animals were slaughtered at the USU Matthew Hillyard Animal, Teaching, and Research Center (Wellsville, UT) at approximately 18 mo of age, after $111 \mathrm{~d}$ on each finishing diet. The resulting carcasses represented grass-finished (USUGrass), birdsfoot trefoil-finished (USUBFT), or grain-finished (USUGrain) beef. Carcasses were chilled for $24 \mathrm{~h}$ at 2 to $4^{\circ} \mathrm{C}$ prior to fabrication.

\section{Product Fabrication}

Two different boneless subprimals - top sirloin butt (Institutional Meat Purchase Specification [IMPS] number 184; NAMPA, 2010) and shoulder clod (IMPS number 114; NAMPA, 2010)—were collected from each carcass ( $n=6$ per diet). Subprimals were wet-aged under vacuum within plastic barrier bags (Sealed Air Corporation, Charlotte, NC) for $14 \mathrm{~d}$ at 2 to $4^{\circ} \mathrm{C}$ before producing retail steaks. Top sirloin steaks of $2.5 \mathrm{~cm}$ thickness were prepared following the removal of the biceps femoris, gluteus accessories, and gluteus profundus, leaving only the GM muscle. Steaks were hand cut from the GM, progressing anterior to posterior. The infraspinatus and teres major muscles were removed from the aged shoulder clod, and beef arm steaks (IMPS number 114E; NAMPA, 2010) were produced from only the TB muscle. Prior to cutting steaks, the small elongated side muscle was removed from the center TB. Then, the lateral head of the TB was removed at the natural seam between the lateral head and the long head of the TB. After separation, the exposed internal connective tissue previously located between the heads was removed. Finally, $2.5-\mathrm{cm}-$ thick steaks were cut from the long head of the TB by hand cutting perpendicular to the muscle fibers. All steaks were randomly assigned to each measurement, individually vacuum packaged, and stored at $-20^{\circ} \mathrm{C}$ until further analysis.

\section{Sample Preparation for Proximate, pH, and Fatty Acid Analysis}

Raw steaks were thawed for $24 \mathrm{~h}$ at 4 to $6^{\circ} \mathrm{C}$. Any residual heavy connective tissue and/or external fat were removed, leaving only the TB or GM. Samples 
were cubed, submerged in liquid nitrogen, placed in a blender (Vita-Mix Corp., Cleveland, $\mathrm{OH}$; model number VM0100A), and pulverized to form beef homogenates. Powdered samples were double packed in VWR sample bags (BPR-4590; VWR, Radnor, PA) and stored at $-80^{\circ} \mathrm{C}$ for subsequent analysis (Martin et al., 2013).

\section{Proximate Analysis}

A chloroform:methanol extraction method was used for determination of total intramuscular fat (IMF), similar to Folch et al. (1957). One gram of each homogenized sample was weighed into 50-mL centrifuge tubes (VWR; North American catalog number 89039-656) along with $3.2 \mathrm{~mL}$ of distilled water and vortexed. Eight milliliters each of methanol and chloroform were added and vortexed for $2 \mathrm{~min}$. Four milliliters of water was added to samples, which were vortexed for an additional $30 \mathrm{~s}$. This mixture was centrifuged at $2,360 \times g$ for $10 \mathrm{~min}$ at $25^{\circ} \mathrm{C}$. Four milliliters of the chloroform layer was pipetted into labeled and preweighed disposable 50-mL culture tubes. Chloroform extracts were evaporated to dryness through an initial 10 min heating on an electric dry heating block before finishing evaporation in an oven $\left(101^{\circ} \mathrm{C}\right)$ to a constant weight. Tubes were cooled in a desiccator and weighed. The total fat percentage was calculated as fat $(\%)=($ weight of fat residue/sample weight $) \times 2 \times 100$.

An AOAC oven-drying method was used to determine total moisture (method 950.46b; AOAC, 1995). The percentage of moisture was calculated as moisture $(\%)=[($ wet weight - dry weight $) /$ wet weight $] \times 100$. Percent ash was determined through heating in a muffle furnace at 550 to $600^{\circ} \mathrm{C}$ for at least $24 \mathrm{~h}$ (method 920.153; AOAC, 1995). Incinerated samples were removed from the furnace and allowed to cool in a desiccator before weighing. The percentage of ash was calculated as ash $(\%)=($ ash weight/initial weight $) \times$ 100. Protein percent was determined by a dye-binding method (method 2011.04; AOAC, 2011) using a CEM Sprint Protein Analyzer (CEM Corp., Matthews, NC) as described by Moser and Herman (2011).

\section{pH Analysis}

A benchtop $\mathrm{pH}$ meter (Orion 3 Star; Thermo Electron Corporation, Beverly, MA) was used to determine the $\mathrm{pH}$ of homogenized samples. Five grams of homogenized sample was weighed into 50-mL (VWR) disposable culture tubes. Forty-five milliliters of distilled water was added to the culture tube, which was vortexed until all meat was dispersed. A filter paper (VWR; North American catalog number 28320-085) folded in the form of a cone was immersed in the culture tube and then the
$\mathrm{pH}$ electrode was immersed in the solution that seeped into the filter paper cone (John et al., 2004).

\section{Fatty Acid Analysis}

Fatty acid methyl esters (FAME) were prepared by the method described by O'Fallon et al. (2007). One gram of raw meat homogenate was weighed into a screw-cap glass vial along with an internal standard solution of tridecanoic acid $(0.5 \mathrm{mg} / \mathrm{mL}$ in methanol; T-135; Nu-Chek Prep, Inc., Elysian, MN), and the vial was sealed with a polypropylene lined cap (Thermo Fisher, Waltham, MA). Vials were placed in a water bath (catalog number 67120; The Precision Scientific Co. Chicago, IL) for incubation at $55^{\circ} \mathrm{C}$. Hexane was used to extract FAME prior to analysis by gas chromatography.

Separation of FAME was performed by a Shimadzu gas chromatograph (GC-2010; Shimadzu Corporation, Kyoto, Japan) equipped with a HP-88 capillary column ( $100 \mathrm{~m}$ by $0.25 \mathrm{~mm}$ by $0.20 \mu \mathrm{m}$; Agilent Technologies, Inc., Palo Alto, CA) and a flame ionization detector. The gas chromatograph was operated based on the conditions described by Tansawat et al. (2013). The column head pressure was $195.6 \mathrm{kPa}$ and the total flow rate was $129.1 \mathrm{~mL} / \mathrm{min}(2.47 \mathrm{~mL} / \mathrm{min}$ column flow and $3.0 \mathrm{~mL} / \mathrm{min}$ purge flow). One microliter of sample was injected with a split ratio of 50:1. The oven method was as follows: $35^{\circ} \mathrm{C}$ held for $2 \mathrm{~min}$, increased to a temperature of $170^{\circ} \mathrm{C}$ at a rate of $4^{\circ} \mathrm{C} / \mathrm{min}$, held for 4 $\mathrm{min}$, then increased to a temperature of $240^{\circ} \mathrm{C}$ at a rate of $3.5^{\circ} \mathrm{C} / \mathrm{min}$, and held for $7 \mathrm{~min}$. Hydrogen was used as the carrier gas. The injector and flame ionization detector were operated at $250^{\circ} \mathrm{C}$. Fatty acids were identified based on the similarity of retention times with gas chromatography reference standards (Nu-Chek Prep, Inc.). Fatty acid concentrations were calculated relative to initial wet sample weight $(\mathrm{mg} / \mathrm{g})$.

\section{Consumer Sensory Evaluation}

Sensory evaluation was conducted at the USU Department of Nutrition, Dietetics, and Food Sciences (Logan, UT) as per an approved human subject protocol (USU Institutional Review Board number 4760), similar to the protocols of Maughan et al. (2012). Six replicates comprising the 6 diet and muscle combinations were conducted with 120 panelists in each replicate. Each replicate occurred on separate days and only one animal replicate was represented within each sensory panel replicate. Prior to consumer evaluation, steaks were thawed for $24 \mathrm{~h}$ at $4^{\circ} \mathrm{C}$. Steaks were cooked using Presto Tiltn' Drain electric griddles (42096US; National Presto Industries, Inc., Eau Claire, WI) to a medium degree of doneness $\left(70^{\circ} \mathrm{C}\right)$ determined with a digital thermometer 
(Atkins Temp tech digital thermometer; Cooper-Atkins Corporation, Middlefield, CT) equipped with a fast responding microneedle probe. The temperature was read by inserting the probe parallel to the surface of the griddle to the geometric center of the steak. Immediately after cooking, any external fat or heavy connective tissues were removed from the cooked steaks, leaving the TB or GM for evaluation. Steaks were cut into 8 to 12 cubes ( 2.5 by $2.5 \mathrm{~cm}$ by cooked thickness), placed in covered aluminum dishes, and held for no more than 5 min in a warming oven $\left(65 \pm 3^{\circ} \mathrm{C}\right)$. One cube per sample was served warm to consumers under red lighting. Consumers were provided with toothpicks, a napkin, a cup of water, and palate cleansers (unsalted crackers).

Each sample was evaluated for aroma, flavor, tenderness, juiciness, fattiness, and overall liking on a hedonic scale of 9, with 1 being "dislike extremely" and 9 being "like extremely." For aroma, panelists were instructed to uncover samples and sniff the cooked sample. All other attributes were evaluated during mastication of samples. A 4-point hedonic scale was used for assessment of perceived quality, where 1 = unsatisfactory, 2 = everyday quality, $3=$ better than everyday quality, and $4=$ premium quality. Additionally, consumers were asked for anonymous demographic information along with consumption and preference information for beef. Preference data was collected using a 10-mm continuous line scale on which $0=$ extremely unimportant and $10=$ extremely important.

\section{Warner-Bratzler Shear Force Analysis}

Objective tenderness was determined by WBSF according to American Meat Science Association guidelines (AMSA, 2015). Steaks were thawed for $24 \mathrm{~h}$ until an internal temperature of 4 to $6^{\circ} \mathrm{C}$ was reached and then cooked as previously described. Cooked steaks were cooled overnight $\left(4-6^{\circ} \mathrm{C}\right)$ and tempered $3 \mathrm{~h}$ at room temperature $\left(24-26^{\circ} \mathrm{C}\right)$ prior to coring. Six $1.27-\mathrm{cm}$ cores per steak sample were removed parallel to the longitudinal orientation of the muscle fiber of the TB or GM. Each core was sheared once on a TMS-Pro Texture Analyzer (FTC 500N ILC; Food Technology Corporation, Sterling, VA) with a WBSF attachment using a $200 \mathrm{~mm} / \mathrm{min}$ crosshead speed and a 50-kg load cell.

\section{Volatile Compound Analysis}

Analysis of volatile compounds was performed as outlined by Chail et al. (2016). Cooking protocols were the same as those previously described. Immediately after cooking, five $1.27-\mathrm{cm}$ cores were extracted by coring perpendicular to the surface of the steak cut surface. Cores were then minced for $10 \mathrm{~s}$ in a coffee-bean grinder (KRUPS, Medford, MA; type number F203). Five grams of the minced sample were weighed into $20-\mathrm{mL}$ glass vials (093640-036-00; Gerstel Inc., Linthicum, MD) and closed with a polytetrafluoroethylene septa and screw cap (093640-092-00; Gerstel Inc.). Ten microliters of internal standard (1,2-dichlorobenzene; $0.801 \mathrm{mg} / \mathrm{mL}$ ) was added and the vial was loaded by a Gerstel automated sampler (MPS; Gerstel Inc.) for a 5 min incubation period at $65^{\circ} \mathrm{C}$ in the Gerstel agitator $(500$ rotations per min; Gerstel Inc.) followed by $20 \mathrm{~min}$ of extraction where volatile compounds were collected from the headspace of cooked samples by solid-phase microextraction using an $85-\mu \mathrm{m}$ film thickness carboxen polydimethylsiloxane fiber (Supelco Inc., Bellefonte, PA). Extracted volatile compounds were injected on a VF-5 ms capillary column $(30 \mathrm{~m} \times 0.25 \mathrm{~mm} \times 1.00 \mu \mathrm{m}$; Agilent J\&W GC Column; Agilent Technologies, Inc., Santa Clara, CA). Authentic standards were purchased from Sigma-Aldrich (St. Louis, MO) and used to validate compound identities through comparison of retention times and ion fragmentation patterns. Quantitation was performed by an internal standard calibration with the same authentic standards.

\section{Statistical Analysis}

A generalized linear mixed model using PROC GLIMMIX of SAS (version 9.3; SAS Inst. Inc., Cary, NC) was used for statistical analysis. Two-way ANOVA was used to determine the effect of diet, muscle, or any interaction of diet with muscle. Carcass served as the experimental unit. Denominator degrees of freedom were calculated by the Kenward-Rogers approximation. Perceived quality level was analyzed by the GLIMMIX procedure of SAS using the ILINK option of the LSMEANS statement for the calculation of least squares means of proportions. All treatment mean separation was conducted using a protected $t$ test by the LSMEANS/PDIFF option of the GLIMMIX procedure. Statistical significance was determined at $P \leq 0.05$. For all cooked measurements, final internal temperature was determined not to differ due to treatment factors $(P>0.05)$. Therefore, final internal temperature was not included in the model.

\section{RESULTS}

\section{Proximate Composition and $\mathrm{pH}$}

Proximate composition and $\mathrm{pH}$ values for raw beef steaks are presented in Table 1. None of these components were determined to be dependent on an interaction between diet and muscle $(P \geq 0.220)$. However, diet was determined to impact moisture, ash, and IMF percent $(P \leq 0.034)$. Moisture percentage was greater $(P<$ $0.05)$ in USUGrass beef compared with USUGrain beef. Meanwhile, USUBFT beef moisture percent was similar 
Table 1. Effects of beef finishing $\operatorname{diet}^{1}$ and muscle ${ }^{2}$ on percentages of moisture, ash, intramuscular fat (IMF), protein, and $\mathrm{pH}$ of raw steaks

\begin{tabular}{|c|c|c|c|c|c|c|c|c|c|c|}
\hline \multirow[b]{3}{*}{ Component } & \multicolumn{6}{|c|}{ Finishing diet and muscle } & \multirow[b]{3}{*}{ SEM $^{3}$} & & & \\
\hline & \multicolumn{2}{|c|}{ USUGrain } & \multicolumn{2}{|c|}{ USUBFT } & \multicolumn{2}{|c|}{ USUGrass } & & \multicolumn{3}{|c|}{$P$-value } \\
\hline & GM & TB & $\mathrm{GM}$ & $\mathrm{TB}$ & GM & $\mathrm{TB}$ & & Diet & Muscle & Diet $\times$ muscle \\
\hline Moisture, \% & $73.23^{y}$ & $74.32^{y}$ & $74.23^{x y}$ & $74.89^{x y}$ & $75.03^{x}$ & $75.91^{x}$ & 0.38 & 0.007 & 0.003 & 0.770 \\
\hline Ash, $\%$ & $1.05^{\mathrm{y}}$ & $1.02^{\mathrm{y}}$ & $1.11^{\mathrm{x}}$ & $1.07^{\mathrm{x}}$ & $1.11^{\mathrm{x}}$ & $1.05^{\mathrm{x}}$ & 0.01 & 0.004 & $<0.001$ & 0.400 \\
\hline IMF, \% & $3.99^{\mathrm{x}}$ & $4.32^{\mathrm{x}}$ & $2.92^{x y}$ & $3.31^{x y}$ & $2.60^{y}$ & $2.80^{\mathrm{y}}$ & 0.39 & 0.034 & 0.092 & 0.900 \\
\hline Protein, $\%$ & 22.64 & 21.48 & 22.83 & 22.16 & 22.43 & 21.54 & 0.27 & 0.267 & $<0.001$ & 0.520 \\
\hline $\mathrm{pH}$ & 5.59 & 5.77 & 5.63 & 5.77 & 5.64 & 5.98 & 0.06 & 0.075 & $<0.001$ & 0.220 \\
\hline
\end{tabular}

$\mathrm{x}, \mathrm{y}$ Within a row, least squares means with different superscripts differ $(P<0.05)$ due to diet.

${ }^{1}$ Finishing diets: USUGrain $=$ grain-finished; USUBFT $=$ birdsfoot trefoil-finished; USUGrass $=$ grass-finished .

${ }^{2} \mathrm{GM}=$ gluteus medius; $\mathrm{TB}=$ triceps brachii.

${ }^{3}$ Pooled (largest) SE of least squares mean.

$(P>0.05)$ that that of both USUGrass and USUGrain beef. Ash percent was similar $(P>0.05)$ between USUGrass and USUBFT, which were each greater $(P$ $<0.05)$ than USUGrain. Lower $(P<0.05)$ IMF percent was determined for USUGrass beef in comparison with USUGrain beef. The IMF percent of USUBFT beef had similarity $(P>0.05)$ with both USUGrass and USUGrain beef. Diet did not impact protein percent or $\mathrm{pH}(P \geq 0.075)$.

Muscle influenced moisture, ash, and protein percent $(P \leq 0.003)$, along with $\mathrm{pH}(P<0.001)$. Muscle did not impact IMF percent $(P=0.092)$. In comparison with muscle type, the TB had greater $(P<0.05)$ moisture percent than the GM. Ash and protein percent was greater $(P<0.05)$ in the GM compared with the TB. Meanwhile, muscle $\mathrm{pH}$ was lower $(P<0.05)$ in the GM compared with the TB.

\section{Fatty Acids}

Concentrations of fatty acids from raw steaks are summarized in Table 2. No prominent individual fatty acid or fatty acid group was impacted by an interaction between diet and muscle $(P \geq 0.051)$, although low quantity behenic acid (22:0) did have a significant interaction $(P=0.016)$. The ratio of $n-6: n-3$ fatty acids was affected by the interaction of muscle $\times \operatorname{diet}(P=0.016)$. Between forage diets (USUGrass and USUBFT), $n$ 6: $n-3$ ratios were similar $(P>0.05)$ between GM and TB, whereas within USUGrain, the GM was greater $(P$ $<0.05$ ) than the TB. Overall, USUGrain steaks (GM and TB) had greater $(P<0.05) n-6: n-3$ ratios in comparison with forage-finished beef steaks. Furthermore, USUGrain GM steaks had greater $(P<0.05) n-6: n-3$ ratios in comparison with USUGrain TB steaks.

Cumulative SFA, MUFA, and PUFA concentrations were each impacted by diet $(P \leq 0.032)$. Cumulative SFA was greater $(P<0.05)$ in USUGrain beef compared with USUGrass beef, but USUBFT beef cumulative SFA was similar $(P>0.05)$ to that of both USUGrain and USUGrass beef. Moreover, cumulative MUFA was greater $(P<0.05)$ in USUGrain beef compared with both USUGrass and USUBFT beef, which did not differ $(P>0.05)$. The concentration of cumulative PUFA was lower $(P<0.05)$ in USUGrass beef in comparison with USUGrain and USUBFT beef, which did not differ $(P>0.05)$.

Diet also influenced individual fatty acid concentrations, where USUGrain beef had greater $(P<0.05)$ content of palmitic (16:0), margaric (17:0), palmitelaidic (16:1 cis-9), oleic (18:1 n-9), octadecenoic (18:1 n-7), and arachidonic (20:4 $n-6)$ acids in comparison with both USUGrass and USUBFT beef, which did not differ $(P>0.05)$. The content of linoleic $(18: 2 n-6)$, linolenic (18:3n-6), eicosadienoic (20:2 n-6), and eicosatrienoic $(20: 3 n-6)$ of USUGrain beef was greater $(P<0.05)$ than that of USUBFT beef, which was greater $(P<0.05)$ than that of USUGrass beef. Moreover, myristoleic (14:1 cis9) acid content of USUBFT beef was comparable $(P>$ 0.05 ) to that of USUGrain and USUGrass beef; however, the content in USUGrain beef was greater $(P<0.05)$ than that of USUGrass beef. The content of $\alpha$-linolenic (18:3 $n-3)$ and eicosapentaenoic (20:5 n-3) acids was greater $(P<0.05)$ in USUBFT beef compared with USUGrass beef and the content of these fatty acids was lower $(P<$ $0.05)$ in USUGrain beef compared with both USUBFT and USUGrass beef. Forage-finished beef (USUGrass and USUBFT) had similar content $(P>0.05)$ of vaccenic acid $(18: 1$ trans-11) but greater $(P<0.05)$ content in comparison with USUGrain beef.

Muscle type impacted concentrations of some individual fatty acids. Myristoleic (14:1 cis-9; $P=0.020)$, vaccenic (18:1 trans-11; $P=0.017)$, eicosapentaenoic (20:5 n-3; $P<0.001)$, and conjugated linoleic (CLA cis9 , trans-11; $P=0.008$ ) acids were each greater in the TB compared with the GM. Meanwhile, arachidonic (20:4 $n-6 ; P=0.002)$ and eicosatrienoic $(20: 3 n-6 ; P=0.015)$ acids were each greater in the GM compared with the TB. 
Table 2. Effects beef of finishing $\operatorname{diet}^{1}$ and muscle ${ }^{2}$ on concentrations ( $\mathrm{mg} / \mathrm{g}$ wet basis) of individual fatty acids and fatty acid categories (SFA, MUFA, and PUFA) of raw steaks

\begin{tabular}{|c|c|c|c|c|c|c|c|c|c|c|}
\hline \multirow{3}{*}{$\begin{array}{l}\text { Fatty acids, } \\
\text { mg/g wet } \\
\text { sample }\end{array}$} & \multicolumn{6}{|c|}{ Finishing diet and muscle } & \multirow[b]{3}{*}{ SEM $^{3}$} & \multirow{2}{*}{\multicolumn{3}{|c|}{$P$-value }} \\
\hline & \multicolumn{2}{|c|}{ USUGrain } & \multicolumn{2}{|c|}{ USUBFT } & \multicolumn{2}{|c|}{ USUGrass } & & & & \\
\hline & GM & TB & GM & TB & GM & TB & & Diet & Muscle & Diet $\times$ muscle \\
\hline $\begin{array}{l}\text { SFA } \\
\end{array}$ & $20.45^{\mathrm{x}}$ & $16.93^{\mathrm{x}}$ & $12.19^{\mathrm{xy}}$ & $14.13^{x y}$ & $10.57^{\mathrm{y}}$ & $11.95^{\mathrm{y}}$ & 2.13 & 0.032 & 0.957 & 0.167 \\
\hline 10:0 & 0.02 & 0.02 & 0.01 & 0.02 & 0.01 & 0.02 & 0.01 & 1.060 & 0.395 & 0.730 \\
\hline 12:0 & 0.02 & 0.02 & 0.02 & 0.02 & 0.02 & 0.02 & 0.01 & 0.675 & 0.087 & 0.458 \\
\hline 14:0 & 1.00 & 0.93 & 0.64 & 0.83 & 0.57 & 0.71 & 0.13 & 0.179 & 0.239 & 0.325 \\
\hline 15:0 & 0.18 & 0.17 & 0.14 & 0.18 & 0.13 & 0.17 & 0.02 & 0.627 & 0.057 & 0.192 \\
\hline $16: 0$ & $12.58^{\mathrm{x}}$ & $10.63^{x}$ & $7.16^{\mathrm{y}}$ & $8.26^{\mathrm{y}}$ & $6.06^{\mathrm{y}}$ & $6.78^{y}$ & 1.36 & 0.019 & 0.955 & 0.241 \\
\hline $17: 0$ & $0.51^{\mathrm{x}}$ & $0.42^{\mathrm{x}}$ & $0.29^{\mathrm{y}}$ & $0.34^{\mathrm{y}}$ & $0.24^{\mathrm{y}}$ & $0.29^{\mathrm{y}}$ & 0.05 & 0.011 & 0.891 & 0.150 \\
\hline 18:0 & 6.04 & 4.66 & 3.84 & 4.35 & 3.45 & 3.85 & 0.58 & 0.070 & 0.646 & 0.066 \\
\hline 19:0 & 0.05 & 0.04 & 0.05 & 0.07 & 0.05 & 0.07 & 0.01 & 0.239 & 0.055 & 0.058 \\
\hline 20:0 & 0.04 & 0.03 & 0.03 & 0.04 & 0.03 & 0.04 & $<0.01$ & 0.900 & 0.576 & 0.055 \\
\hline 22:0 & 0.01 & 0.01 & 0.01 & 0.01 & 0.01 & 0.01 & $<0.01$ & 0.665 & 0.069 & 0.016 \\
\hline MUFA & $18.84^{\mathrm{x}}$ & $20.19^{x}$ & $11.65^{y}$ & $14.22^{\mathrm{y}}$ & $9.66^{\mathrm{y}}$ & $11.45^{\mathrm{y}}$ & 2.26 & 0.001 & 0.311 & 0.964 \\
\hline $14: 1$ cis-9 & $0.22^{\mathrm{x}}$ & $0.26^{\mathrm{x}}$ & $0.13^{x y}$ & $0.19^{x y}$ & $0.12^{\mathrm{y}}$ & $0.16^{\mathrm{y}}$ & 0.03 & 0.047 & 0.020 & 0.820 \\
\hline 16:1 trans -9 & 0.13 & 0.12 & 0.12 & 0.15 & 0.12 & 0.14 & 0.01 & 0.898 & 0.127 & 0.155 \\
\hline 16:1 cis-9 & $1.64^{\mathrm{x}}$ & $1.68^{\mathrm{x}}$ & $0.91^{\mathrm{y}}$ & $1.25^{\mathrm{y}}$ & $0.79^{\mathrm{y}}$ & $1.02^{\mathrm{y}}$ & 0.19 & 0.014 & 0.082 & 0.532 \\
\hline 18:1 trans -11 & $0.21^{\mathrm{y}}$ & $0.18^{\mathrm{y}}$ & $0.39^{x}$ & $0.56^{\mathrm{x}}$ & $0.35^{\mathrm{x}}$ & $0.48^{\mathrm{x}}$ & 0.05 & 0.002 & 0.017 & 0.051 \\
\hline $18: 1 n-9$ & $15.81^{\mathrm{x}}$ & $17.17^{\mathrm{x}}$ & $9.73^{\mathrm{y}}$ & $11.59^{y}$ & $7.94^{y}$ & $9.24^{y}$ & 2.04 & 0.002 & 0.374 & 0.989 \\
\hline $18: 1 n-7$ & $0.82^{x}$ & $0.78^{x}$ & $0.38^{\mathrm{y}}$ & $0.47^{\mathrm{y}}$ & $0.34^{\mathrm{y}}$ & $0.41^{\mathrm{y}}$ & 0.07 & $<0.001$ & 0.384 & 0.448 \\
\hline PUFA & $2.24^{\mathrm{x}}$ & $2.04^{\mathrm{x}}$ & $2.25^{\mathrm{x}}$ & $2.33^{\mathrm{x}}$ & $1.87^{\mathrm{y}}$ & $1.91^{\mathrm{y}}$ & 0.09 & 0.005 & 0.706 & 0.200 \\
\hline $18: 2 n-6$ & $1.28^{\mathrm{x}}$ & $1.19^{\mathrm{x}}$ & $1.08^{\mathrm{y}}$ & $1.11^{\mathrm{y}}$ & $0.91^{\mathrm{z}}$ & $0.93^{z}$ & 0.05 & $<0.001$ & 0.685 & 0.263 \\
\hline $18: 3 n-6$ & $0.02^{\mathrm{x}}$ & $0.02^{\mathrm{x}}$ & $0.01^{\mathrm{y}}$ & $0.01^{\mathrm{y}}$ & $0.01^{z}$ & $0.01^{z}$ & 0.00 & $<0.001$ & 0.587 & 0.302 \\
\hline $18: 3 n-3$ & $0.21^{z}$ & $0.18^{\mathrm{z}}$ & $0.40^{\mathrm{x}}$ & $0.46^{\mathrm{x}}$ & $0.26^{\mathrm{y}}$ & $0.29^{\mathrm{y}}$ & 0.03 & $<0.001$ & 0.202 & 0.068 \\
\hline $20: 2 n-6$ & $0.03^{\mathrm{x}}$ & $0.03^{\mathrm{x}}$ & $0.02^{\mathrm{y}}$ & $0.02^{\mathrm{y}}$ & $0.01^{\mathrm{z}}$ & $0.02^{\mathrm{z}}$ & $<0.01$ & 0.001 & 0.345 & 0.259 \\
\hline $20: 3 n-6$ & $0.06^{\mathrm{x}}$ & $0.05^{\mathrm{x}}$ & $0.04^{\mathrm{y}}$ & $0.03^{\mathrm{y}}$ & $0.02^{\mathrm{z}}$ & $0.01^{\mathrm{z}}$ & $<0.01$ & $<0.001$ & 0.015 & 0.085 \\
\hline $20: 4 n-6$ & $0.53^{\mathrm{x}}$ & $0.48^{\mathrm{x}}$ & $0.48^{\mathrm{y}}$ & $0.42^{\mathrm{y}}$ & $0.47^{\mathrm{y}}$ & $0.44^{\mathrm{y}}$ & 0.02 & 0.046 & 0.002 & 0.803 \\
\hline $20: 5 n-3$ & $0.05^{z}$ & $0.07^{\mathrm{z}}$ & $0.11^{\mathrm{x}}$ & $0.12^{\mathrm{x}}$ & $0.10^{\mathrm{y}}$ & $0.11^{\mathrm{y}}$ & $<0.01$ & $<0.001$ & $<0.001$ & 0.909 \\
\hline $22: 6 n-3$ & 0.02 & 0.03 & 0.03 & 0.04 & 0.02 & 0.03 & $<0.01$ & 0.420 & 0.118 & 0.587 \\
\hline CLA cis-9, trans-11 & $0.08^{\mathrm{y}}$ & $0.07^{\mathrm{y}}$ & $0.09^{\mathrm{x}}$ & $0.14^{\mathrm{x}}$ & $0.07^{x y}$ & $0.10^{\mathrm{xy}}$ & 0.01 & 0.029 & 0.008 & 0.051 \\
\hline Total unknown & $1.89^{\mathrm{x}}$ & $1.86^{\mathrm{x}}$ & $1.43^{x y}$ & $1.74^{x y}$ & $1.31^{\mathrm{y}}$ & $1.51^{\mathrm{y}}$ & 0.14 & 0.042 & 0.105 & 0.317 \\
\hline PUFA:SFA & $0.12^{\mathrm{y}}$ & $0.13^{\mathrm{y}}$ & $0.20^{\mathrm{x}}$ & $0.19^{\mathrm{x}}$ & $0.19^{x y}$ & $0.17^{x y}$ & 0.02 & 0.039 & 0.267 & 0.348 \\
\hline$n-6: n-3$ & $6.72^{\mathrm{a}}$ & $6.30^{\mathrm{b}}$ & $2.91^{\mathrm{cd}}$ & $2.71^{\mathrm{d}}$ & $3.67^{\mathrm{c}}$ & $3.51^{\mathrm{cd}}$ & 0.28 & $<0.001$ & 0.807 & 0.016 \\
\hline
\end{tabular}

${ }^{\mathrm{a}-\mathrm{d}}$ Within a row, least squares means with different superscripts $\operatorname{differ}(P<0.05)$ due to diet $\times$ muscle interaction.

${ }^{\mathrm{x}-\mathrm{z}}$ Within a row, least squares means with different superscripts differ $(P<0.05)$ due to diet.

${ }^{1}$ Finishing diets: USUGrain = grain-finished; USUBFT $=$ birdsfoot trefoil-finished; USUGrass $=$ grass-finished.

${ }^{2} \mathrm{GM}=$ gluteus medius; $\mathrm{TB}=$ triceps brachii

${ }^{3}$ Pooled (largest) SE of least squares mean.

\section{Description of Consumer Participants}

Consumer demographic data are presented in Table 3. The age and gender percentages were similar to previous USU studies. A large number of participants were between 18 and 29 yr of age because recruitment was performed through on-campus advertisement. Among participants, $43.71 \%$ selected beef as their meat of choice, with $48.47 \%$ consuming beef once a week or more often (Table 4). Consumers selected flavor as the more important palatability trait with more frequency than tenderness and juiciness $(53.75,37.05$, and $9.21 \%$, respectively). Participants had no clear partiality to beef type. The majority of consumers $(67.12 \%)$ indicated beef type "doesn't matter," whereas $18.66 \%$ preferred grass fed and $14.21 \%$ preferred grain fed. When asked to rate the importance of brand, country of origin, natural or organic claims, price, and USDA grade of beef (Table 5), price was rated most important $(P<0.05)$. The second most important factor was USDA grade followed by country of origin, natural or organic claims, and brand name, each differing $(P<0.05)$ in order.

\section{Consumer Sensory Evaluation and Warner-Bratzler Shear Force}

Results obtained through consumer sensory evaluation and WBSF are presented in Table 6. Tenderness, 
Table 3. Data on consumer demographic, most important palatability traits, type of beef, and type of meat product

\begin{tabular}{|c|c|c|}
\hline Categories & Options & Percentages \\
\hline \multirow[t]{5}{*}{$\overline{\text { Age }}$} & $18-29$ & 72.83 \\
\hline & $30-39$ & 12.40 \\
\hline & $40-49$ & 7.10 \\
\hline & $50-60$ & 5.16 \\
\hline & Over 60 & 2.51 \\
\hline \multirow[t]{2}{*}{ Gender } & Male & 56.42 \\
\hline & Female & 43.58 \\
\hline \multirow{6}{*}{$\begin{array}{l}\text { Ethnic } \\
\text { origin }\end{array}$} & African-American & 0.69 \\
\hline & Asian & 11.43 \\
\hline & Caucasian/White & 83.83 \\
\hline & Hispanic & 3.62 \\
\hline & Native American & 0.00 \\
\hline & Other & 0.42 \\
\hline \multirow[t]{6}{*}{ Income } & Under $\$ 25,000$ & 54.59 \\
\hline & $\$ 25,000-\$ 34,999$ & 9.61 \\
\hline & $\$ 35,000-\$ 49,999$ & 7.93 \\
\hline & $\$ 50,000-\$ 74,999$ & 13.51 \\
\hline & $\$ 75,000-\$ 100,000$ & 7.95 \\
\hline & More than $\$ 100,000$ & 6.41 \\
\hline \multirow{7}{*}{$\begin{array}{l}\text { Education } \\
\text { level }\end{array}$} & Non-high school graduate & 0.42 \\
\hline & High school graduate & 2.93 \\
\hline & Some college/technical school & 24.23 \\
\hline & College bachelor & 41.62 \\
\hline & Master degree & 17.00 \\
\hline & Professional degree (e.g., MD, JD) & 2.79 \\
\hline & Doctorate & 11.02 \\
\hline
\end{tabular}

fattiness, juiciness, overall liking, and WBSF were impacted by the interaction of muscle $\times \operatorname{diet}(P \leq 0.003)$. Tenderness assessed by consumers was in agreement with instrumental WBSF values, where the GM and TB of USUGrain beef had similar $(P>0.05)$ tenderness. However, in both USUBFT and USUGrass beef, the GM was determined to be more tender $(P<0.05)$ than the TB. Overall, consumers rated USUGrain GM, USUGrain TB, USUBFT GM, and USUGrass GM to have similar $(P>$ $0.05)$ tenderness, whereas USUGrass TB was the least $(P<0.05)$ tender, being comparable $(P>0.05)$ to only USUBFT TB. In agreement with consumers, WBSF values indicated the least $(P<0.05)$ amount of tenderness for USUBFT TB and USUGrass TB.

Both overall liking and fattiness did not differ $(P>$ 0.05 ) between the GM and TB within USUGrain beef. However, in the case of USUBFT and USUGrass beef, the GM was rated to have greater $(P<0.05)$ overall liking and fattiness in comparison with the TB. In comparison of all diet and muscle combinations, USUBFT TB and USUGrass TB were similar $(P>$ $0.05)$ and each had the lowest $(P<0.05)$ overall liking in comparison with all other combinations. Moreover, juiciness was rated similarly $(P>0.05)$ for the GM and TB of USUBFT and USUGrass beef. However,
Table 4. Consumer participant's beef consumption frequency, most important palatability trait, preferred type of beef, and preferred meat product

\begin{tabular}{llc}
\hline \hline Selection options & Beef consumption inquiry & Percentage \\
\hline Frequency of & Less often than once a year & 0.42 \\
consumption of beef & Once or twice a year & 1.95 \\
& Once every 4 to 6 mo & 3.35 \\
& Once every 2 to 3 mo & 5.42 \\
& Once a month/every 4 wk & 10.73 \\
& Once every 2 to 3 wk & 29.66 \\
Most important & Once a week or more often & 48.47 \\
palatability trait & Flavor & 53.75 \\
& Tenderness & 37.05 \\
Type of beef & Juiciness & 9.21 \\
& Grain fed & 14.21 \\
& Grass fed & 18.66 \\
Meat product & Does not matter & 67.12 \\
& Beef & 43.71 \\
& Chicken & 22.84 \\
& Fish & 6.82 \\
& Lamb & 8.09 \\
& Pork & 13.80 \\
& Shellfish & 0.70 \\
& Turkey & 2.09 \\
& Veal & 0.84 \\
& Venison (deer) & 1.12 \\
\hline
\end{tabular}

USUGrain TB was more juicy $(P<0.05)$ in comparison with USUGrain GM.

Steak aroma liking was affected by diet $(P=$ $0.018)$. The aroma of USUGrain beef was more liked $(P<0.05)$ by consumers in comparison with both USUBFT and USUGrass beef, which did not differ $(P>0.05)$. Furthermore, flavor was impacted by muscle type $(P<0.001)$, where the GM had greater $(P<$ $0.05)$ flavor liking compared with the TB.

Consumers also assigned perceived quality level for each beef type (Table 7). An interaction between diet and muscle was present for both the "unsatisfactory" and "premium quality" quality levels $(P=0.020$ and $P=0.002$, respectively). Consumers determined the TB of both USUBFT and USUGrass beef to be "unsatisfactory" more frequently $(P<0.05)$ in comparison with the corresponding forage-finished GM and the GM and TB of USUGrain beef, which had similar $(P>0.05)$ frequency for "unsatisfactory." The opposite of this was determined for consumer perception of "premium quality." The rating of "premium quality" for USUGrain GM, USUGrain TB, and forage-finished (USUGrass and USUBFT) GM was similar $(P>0.05)$ and the frequency of "premium quality" for these was greater $(P<$ $0.05)$ than ratings of USUBFT TB and USUGrass TB.

Diet was determined to impact consumer rating frequency of "good everyday quality" $(P=0.025)$ and "better than everyday quality" $(P=0.005)$. Consumers 
Table 5. Consumer rating on importance of various factors while buying meat

\begin{tabular}{lc}
\hline \hline Factors & Importance $^{1}$ \\
\hline Brand name & $3.79^{\mathrm{e}}$ \\
Country of origin & $4.94^{\mathrm{c}}$ \\
Natural or organic claims & $4.36^{\mathrm{d}}$ \\
Price & $7.70^{\mathrm{a}}$ \\
USDA grade & $6.67^{\mathrm{b}}$ \\
$\mathrm{SEM}^{2}$ & 0.10 \\
$P$-value & $<0.001$ \\
\hline \multicolumn{2}{c}{ a-e Least squares means with different superscripts differ $(P<0.05)}$. \\
\multicolumn{2}{l}{${ }^{1}$ Factor importance was determined using a $10-$ mm continuous line } \\
scale on which 0 = extremely unimportant and $10=$ extremely important. \\
${ }^{2}$ Pooled (largest) SE of least squares mean.
\end{tabular}

evaluated USUGrass beef to be of "good everyday quality" more frequently $(P<0.05)$ in comparison with USUGrain and USUBFT beef, which did not differ $(P>$ 0.05). Meanwhile, USUGrain and USUBFT beef were similar $(P>0.05)$ and determined to have greater $(P<$ $0.05)$ ratings for "better than everyday quality" compared with USUGrass beef. Furthermore, muscle influenced ratings for "better than everyday quality" $(P=$ 0.007), with the GM being greater than the TB.

\section{Volatile Compounds}

Thirty-seven volatile compounds were quantified from cooked steaks and are summarized in Table 8 . Among all volatile compounds, only 3-hydroxy-2-butanone was determined to have a diet $\times$ muscle interaction $(P=0.011)$. Within USUGrain and USUGrass beef, 3-hydroxy-2-butanone was similar $(P>0.05)$ between the GM and TB. Meanwhile, 3-hydroxy-2-butanone was greater $(P<0.05)$ in the GM of USUBFT beef compared with the corresponding TB.

Diet impacted the quantity of 3 carboxylic acids (butanoic, pentanoic, and octanoic acids; $P \leq 0.044$ ) and octanoic acid, methyl ester $(P=0.035)$. Butanoic acid was greater $(P<0.05)$ in USUBFT beef compared with both USUGrain and USUGrass beef, which did not differ $(P>0.05)$. Pentanoic acid was also greater $(P<$ $0.05)$ in USUBFT beef compared with USUGrass beef; however, the quantity of pentanoic acid of USUGrain beef was similar $(P>0.05)$ to that of both USUBFT and USUGrass beef. Octanoice acid was similar $(P<0.05)$ between USUGrass and USUBFT beef and each were greater $(P<0.05)$ than USUGrain beef. The quantity of octanoic acid, methyl ester, was greater $(P<0.05)$ in USUGrass beef compared with USUGrain beef, whereas the quantity in USUBFT beef was similar $(P>0.05)$ to that in both USUGrain and USUGrass beef.

Muscle had a larger influence on volatile compound quantity, with 16 separate compounds differing between muscles $(P \leq 0.037)$. Varied types of compounds were impacted by muscles, including Strecker aldehydes (phenylacetaldehyde and 2- and 3-methyl butanal), ketones (2-propanone, 2,3-butanedione, and 2-pentanone), carboxylic acids (butanoic, pentanoic, and octanoic acids), pyrazines (methyl pyrazine, 2,5-dimethyl pyrazine, trimethyl pyrazine, and 2-ethyl-3,5-dimethyl pyrazine), esters (butanoic and octanoic acid, methyl esters), and methional. In each case, the GM had greater $(P<0.05)$ quantities compared with the TB.

\section{DISCUSSION}

Frequently, IMF percent has been related with consumer liking of beef (O'Quinn et al., 2012; Corbin et al., 2015; Legako et al., 2015). In this study, IMF was not influenced by the interaction of diet with muscle; however, diet did impact IMF, with that of USUGrain beef being greater than that of USUGrass beef. Intramuscular fat of USUBFT beef was comparable to that of both USUGrain and USUGrass beef, in agreement with previous data for the LM (Chail et al., 2016). This result indicates that diet has a greater influence on IMF than the muscle types of this study.

The fatty acid content of IMF was also depended on diet. Specifically, the content of cumulative MUFA and oleic acid (18:1 n-9) were elevated in USUGrain beef, which is of interest due to previous correlations with desirable palatability attributes (Dryden and Maechello, 1970; O'Quinn et al., 2016). In this study, flavor liking was not impacted by diet; however, aroma of USUGrain beef was more liked compared with forage-finished beef. Liking of aroma may also be related with decreased content of $n$-3 fatty acids ( $\alpha$-linolenic [18:3 $n$-3], eicosapentaenoic acid [20:5 n-3], and docosahexaenoic acid [22:6 $n-3]$ ) of USUGrain beef compared with forage-finished beef. Increased level of $n-3$ fatty acids has been widely demonstrated to have potential negative organoleptic impacts through greater susceptibility toward oxidative deterioration (Romeu-Nadal et al., 2007; Arab-Tehrany et al., 2012). Conversely, USUGrain beef had greater content of $n-6$ fatty acids (linoleic acid [18:2 $n$-6], $\gamma$-linolenic acid [18:3 n-6], eicosadienoic acid [20:2 $n$-6], dihomo- $\gamma$ linolenic acid [20:3 $n-6]$, and arachidonic acid [20:4 n-6]). The increased content of $n-6$ fatty acids may be a significant contributor to greater aroma liking for USUGrain beef. As previously stated, $n-3$ fatty acids are known to be susceptible to deterioration, and by comparison, $n-6$ fatty acids of beef have fewer carbon chain double bonds overall and, therefore, a lower likelihood for deterioration compared with beef $n-3$ fatty acids.

To a lesser extent, there were parallels between $n-6$ and $n-3$ fatty acids in relation to muscle type and sensory attributes. Consumers determined the GM to have 
Table 6. Effects of beef finishing $\operatorname{diet}^{1}$ and muscle ${ }^{2}$ on consumer liking of aroma, flavor, tenderness, fattiness, juiciness, overall liking, and Warner-Bratzler shear force (WBSF) of cooked steaks

\begin{tabular}{|c|c|c|c|c|c|c|c|c|c|c|}
\hline \multirow[b]{3}{*}{ Attributes ${ }^{3}$} & \multicolumn{6}{|c|}{ Finishing diet and muscle } & \multirow[b]{3}{*}{ SEM $^{4}$} & \multirow{2}{*}{\multicolumn{3}{|c|}{$P$-value }} \\
\hline & \multicolumn{2}{|c|}{ USUGrain } & \multicolumn{2}{|c|}{ USUBFT } & \multicolumn{2}{|c|}{ USUGrass } & & & & \\
\hline & GM & TB & GM & TB & GM & TB & & Diet & Muscle & $\overline{\text { Diet } \times \text { muscle }}$ \\
\hline Aroma & $6.53^{x}$ & $6.32^{\mathrm{x}}$ & $6.39^{y}$ & $6.19^{\mathrm{y}}$ & $6.34^{\mathrm{y}}$ & $6.10^{\mathrm{y}}$ & 0.90 & 0.018 & $<0.001$ & 0.932 \\
\hline Flavor & 6.36 & 6.22 & 6.33 & 5.95 & 6.25 & 5.88 & 0.11 & 0.199 & $<0.001$ & 0.078 \\
\hline Tenderness & $6.22^{\mathrm{ab}}$ & $6.35^{\mathrm{a}}$ & $6.53^{\mathrm{a}}$ & $5.99^{\mathrm{bc}}$ & $6.28^{\mathrm{ab}}$ & $5.77^{\mathrm{c}}$ & 0.15 & 0.215 & $<0.001$ & $<0.001$ \\
\hline Fattiness & $6.11^{\mathrm{ab}}$ & $6.12^{\mathrm{ab}}$ & $6.18^{\mathrm{a}}$ & $5.92^{\mathrm{bc}}$ & $6.15^{\mathrm{ab}}$ & $5.72^{\mathrm{c}}$ & 0.13 & 0.362 & $<0.001$ & 0.002 \\
\hline Juiciness & $5.96^{\mathrm{b}}$ & $6.36^{\mathrm{a}}$ & $6.05^{\mathrm{ab}}$ & $6.04^{\mathrm{ab}}$ & $6.22^{\mathrm{b}}$ & $6.0^{\mathrm{ab}}$ & 0.18 & 0.800 & 0.256 & $<0.001$ \\
\hline Overall liking & $6.25^{\mathrm{a}}$ & $6.25^{\mathrm{a}}$ & $6.24^{\mathrm{a}}$ & $5.86^{\mathrm{b}}$ & $6.24^{\mathrm{a}}$ & $5.71^{b}$ & 0.15 & 0.254 & $<0.001$ & $<0.001$ \\
\hline WBSF, Kgf & $2.72^{\mathrm{bc}}$ & $2.58^{\mathrm{cd}}$ & $2.13^{\mathrm{d}}$ & $3.21^{\mathrm{ab}}$ & $2.66^{\mathrm{c}}$ & $3.65^{\mathrm{a}}$ & 0.20 & 0.008 & $<0.001$ & 0.003 \\
\hline
\end{tabular}

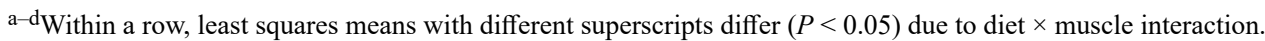

${ }^{\mathrm{x}, \mathrm{y}}$ Within a row, least squares means with different superscripts $\operatorname{differ}(P<0.05)$ due to diet.

${ }^{1}$ Finishing diets: USUGrain = grain-finished; USUBFT $=$ birdsfoot trefoil-finished; USUGrass $=$ grass-finished.

${ }^{2} \mathrm{GM}=$ gluteus medius; $\mathrm{TB}=$ triceps brachii.

${ }^{3}$ Evaluated on a 9 -point hedonic scale $(1=$ dislike extremely and $9=$ like extremely).

${ }^{4}$ Pooled (largest) SE of least square means.

greater flavor and aroma liking compared with the TB. Furthermore, the GM had greater content of $2 n-6$ fatty acids (20:3 n-6 and 20:4 n-6). Meanwhile, the TB had greater content of 22:6n-3. These results again indicate that the muscle types of this study had a lesser influence on fatty acid content compared with diet. These results also indicate that factors beyond fatty acid content may influence the aroma and flavor of different beef muscles. This is in agreement with previous work, which indicated muscle-specific relationships between fatty acids and flavor liking (Hunt et al., 2016).

Although consumer liking of flavor and aroma was not impacted by interacting effects of diet and muscle, interactions were evident for all other sensory attributes and WBSF. Interestingly, these interactions revealed that within forage-finished beef, the GM had greater liking of tenderness, fattiness, overall liking, and WBSF tenderness compared with the TB. However, for the USUGrain treatment, these attributes did not differ between the GM and TB, in agreement with Carmack et al. (1995) and
Mc Keith et al. (1985). These results indicate that muscle has greater influence on tenderness and overall liking for forage-finished beef. Therefore, muscle selection from forage-finished beef is critically important for palatability.

Dissimilar to these results, juiciness was found to be equal within forage-finished beef but differentiated in USUGrain beef. Within USUGrain beef, the TB had greater juiciness compared with the GM, in agreement with past works (Mc Keith et al., 1985; Carmack et al., 1995). Juiciness is known to be related to moisture content (Lucherk et al., 2016). The TB of this study had greater moisture content compared with the GM. It is of interest that the overall moisture of USUGrain beef was lower than that of USUGrass beef. These results indicate that as moisture content was reduced in USUGrain beef, consumer juiciness perception was more discerning. This concept was robustly demonstrated by changes in degree of doneness in recent work (Lucherk et al., 2016). Overall, these results again indicate the importance of muscle selection explicit to finishing diet for palatability traits.

Table 7. Effects of beef finishing $\operatorname{diet}^{1}$ and muscle ${ }^{2}$ on quality level percentages of steaks assessed by consumers

\begin{tabular}{|c|c|c|c|c|c|c|c|c|c|c|}
\hline \multirow[b]{3}{*}{ Quality level $^{3}$} & \multicolumn{6}{|c|}{ Finishing diet and muscle } & \multirow[b]{3}{*}{$\mathrm{SEM}^{4}$} & & & \\
\hline & \multicolumn{2}{|c|}{ USUGrain } & \multicolumn{2}{|c|}{ USUBFT } & \multicolumn{2}{|c|}{ USUGrass } & & \multicolumn{3}{|c|}{$P$-value } \\
\hline & GM & TB & GM & TB & GM & $\mathrm{TB}$ & & Diet & Muscle & Diet $\times$ muscle \\
\hline Unsatisfactory & $14.3^{\mathrm{b}}$ & $14.3^{\mathrm{b}}$ & $13.3^{\mathrm{b}}$ & $19.2^{\mathrm{a}}$ & $13.6^{\mathrm{b}}$ & $21.6^{\mathrm{a}}$ & 1.7 & 0.102 & $<0.001$ & 0.020 \\
\hline Good everyday quality & $45.8^{\mathrm{y}}$ & $45.4^{\mathrm{y}}$ & $44.4^{\mathrm{y}}$ & $48.5^{y}$ & $48.8^{\mathrm{x}}$ & $51.9^{\mathrm{x}}$ & 2.1 & 0.025 & 0.135 & 0.446 \\
\hline Better than everyday quality & $30.2^{\mathrm{x}}$ & $30.3^{x}$ & $31.7^{\mathrm{x}}$ & $26.1^{\mathrm{x}}$ & $27.8^{\mathrm{y}}$ & $22.4^{\mathrm{y}}$ & 1.9 & 0.005 & 0.007 & 0.132 \\
\hline Premium quality & $9.5^{\mathrm{a}}$ & $9.8^{\mathrm{a}}$ & $10.4^{\mathrm{a}}$ & $6.1^{\mathrm{b}}$ & $9.7^{\mathrm{a}}$ & $4.0^{\mathrm{b}}$ & 1.2 & 0.005 & $<0.001$ & 0.002 \\
\hline
\end{tabular}

a,b Within a row, least squares means with different superscripts differ $(P<0.05)$ due to diet $\times$ muscle interaction.

${ }^{\mathrm{x}, \mathrm{y}}$ Within a row, least squares means with different superscripts $\operatorname{differ}(P<0.05)$ due to diet.

${ }^{1}$ Finishing diets: USUGrain $=$ grain-finished; USUBFT $=$ birdsfoot trefoil-finished; USUGrass $=$ grass-finished.

${ }^{2} \mathrm{GM}=$ gluteus medius; $\mathrm{TB}=$ triceps brachii.

${ }^{3}$ Evaluated on a 4-point hedonic scale ( 1 = unsatisfactory, 2 = good everyday quality, 3 = better than everyday quality, and $4=$ premium quality).

${ }^{4}$ Pooled (largest) SE of least squares mean. 
Table 8. Effects of beef finishing diet $^{1}$ and muscle $^{2}$ on concentrations (ng/g of sample) of volatile compounds from cooked steaks

\begin{tabular}{|c|c|c|c|c|c|c|c|c|c|c|}
\hline \multirow[b]{3}{*}{ Volatile compounds } & \multicolumn{6}{|c|}{ Finishing diet and muscle } & \multirow[b]{3}{*}{ SEM $^{3}$} & \multirow{2}{*}{\multicolumn{3}{|c|}{$P$-value }} \\
\hline & \multicolumn{2}{|c|}{ USUGrain } & \multicolumn{2}{|c|}{ USUBFT } & \multicolumn{2}{|c|}{ USUGrass } & & & & \\
\hline & GM & TB & GM & $\mathrm{TB}$ & GM & $\mathrm{TB}$ & & Diet & Muscle & Diet $\times$ muscle \\
\hline \multicolumn{11}{|l|}{ n-Aldehydes } \\
\hline Acetaldehyde & 8.82 & 9.28 & 10.64 & 7.04 & 9.16 & 7.09 & 1.15 & 0.663 & 0.055 & 0.182 \\
\hline 2-Methyl propanal & 3.62 & 4.64 & 5.14 & 3.36 & 4.53 & 3.08 & 0.64 & 0.733 & 0.137 & 0.053 \\
\hline Hexanal & 20.80 & 19.09 & 22.57 & 13.52 & 14.49 & 16.13 & 3.21 & 0.313 & 0.222 & 0.194 \\
\hline Heptanal & 1.76 & 1.33 & 2.77 & 1.51 & 1.61 & 2.63 & 0.49 & 0.351 & 0.555 & 0.051 \\
\hline Octanal & 2.67 & 1.89 & 3.44 & 2.27 & 2.34 & 3.99 & 0.67 & 0.370 & 0.840 & 0.058 \\
\hline Nonanal & 3.15 & 2.12 & 3.92 & 2.56 & 2.87 & 4.92 & 0.82 & 0.311 & 0.853 & 0.059 \\
\hline Decanal & 0.14 & 0.11 & 0.14 & 0.14 & 0.12 & 0.12 & 0.01 & 0.108 & 0.241 & 0.325 \\
\hline \multicolumn{11}{|l|}{ Strecker aldehydes } \\
\hline 2-Methyl butanal & 7.39 & 6.88 & 8.48 & 5.23 & 8.11 & 3.61 & 1.39 & 0.622 & 0.014 & 0.279 \\
\hline 3-Methyl butanal & 13.76 & 13.16 & 18.46 & 11.69 & 16.25 & 9.26 & 2.19 & 0.539 & 0.007 & 0.204 \\
\hline Benzaldehyde & 2.44 & 2.74 & 3.31 & 2.37 & 3.07 & 2.32 & 0.32 & 0.697 & 0.064 & 0.103 \\
\hline Phenylacetaldehyde & 0.49 & 0.44 & 0.50 & 0.43 & 0.49 & 0.40 & 0.02 & 0.476 & $<0.001$ & 0.687 \\
\hline \multicolumn{11}{|l|}{ Ketones } \\
\hline 3-Hydroxy-2-butanone & $386.36^{\mathrm{b}}$ & $269.51^{b c}$ & $674.33^{\mathrm{a}}$ & $185.79^{\mathrm{c}}$ & $282.50^{\mathrm{bc}}$ & $162.05^{\mathrm{c}}$ & 71.24 & 0.013 & $<0.001$ & 0.011 \\
\hline 2-Propanone & 14.66 & 15.81 & 23.09 & 13.62 & 17.36 & 11.39 & 3.11 & 0.432 & 0.035 & 0.143 \\
\hline 2,3-Butanedione & 22.96 & 14.85 & 32.36 & 12.48 & 19.43 & 8.95 & 3.66 & 0.076 & $<0.001$ & 0.206 \\
\hline 2-Butanone & 9.48 & 11.34 & 13.32 & 8.29 & 11.03 & 7.91 & 1.58 & 0.640 & 0.089 & 0.073 \\
\hline 2-Pentanone & 1.09 & 0.74 & 1.29 & 1.06 & 0.94 & 0.95 & 0.12 & 0.099 & 0.028 & 0.188 \\
\hline 2-Heptanone & 2.40 & 3.78 & 2.00 & 1.75 & 1.54 & 1.49 & 0.65 & 0.128 & 0.331 & 0.179 \\
\hline \multicolumn{11}{|l|}{ Sulfides } \\
\hline Dimethyl sulfide & 3.14 & 2.82 & 3.89 & 3.11 & 3.57 & 2.82 & 0.52 & 0.574 & 0.134 & 0.873 \\
\hline Dimethyl disulfide & 0.47 & 0.52 & 0.52 & 0.49 & 0.40 & 0.37 & 0.07 & 0.123 & 0.995 & 0.756 \\
\hline Carbon disulfide & 4.51 & 5.35 & 8.05 & 3.63 & 5.72 & 5.90 & 1.43 & 0.768 & 0.279 & 0.098 \\
\hline \multicolumn{11}{|l|}{ Thiols } \\
\hline Methional & 1.49 & 1.24 & 1.60 & 1.17 & 1.55 & 1.08 & 0.10 & 0.711 & $<0.001$ & 0.500 \\
\hline \multicolumn{11}{|l|}{ Furans } \\
\hline 2-Pentyl furan & 1.13 & 1.21 & 1.11 & 1.07 & 1.06 & 1.05 & 0.05 & 0.134 & 0.699 & 0.295 \\
\hline \multicolumn{11}{|l|}{ Carboxylic acids } \\
\hline Butanoic acid & $6.07 \mathrm{y}$ & $5.98^{y}$ & $16.50^{\mathrm{x}}$ & $10.32^{\mathrm{x}}$ & $9.15^{\mathrm{y}}$ & $5.92^{\mathrm{y}}$ & 1.85 & 0.002 & 0.032 & 0.215 \\
\hline Pentanoic acid & $1.20^{\mathrm{xy}}$ & $1.04^{\mathrm{xy}}$ & $1.39^{\mathrm{x}}$ & $1.16^{\mathrm{x}}$ & $1.13^{\mathrm{y}}$ & $1.01^{\mathrm{y}}$ & 0.06 & 0.044 & $<0.001$ & 0.334 \\
\hline Hexanoic acid & 1.64 & 1.81 & 2.15 & 1.74 & 1.39 & 1.24 & 0.27 & 0.126 & 0.423 & 0.371 \\
\hline Heptanoic acid & 0.61 & 0.63 & 0.65 & 0.60 & 0.61 & 0.59 & 0.02 & 0.179 & 0.157 & 0.160 \\
\hline Octanoic acid & $0.41^{\mathrm{y}}$ & $0.37^{\mathrm{y}}$ & $0.48^{\mathrm{x}}$ & $0.43^{\mathrm{x}}$ & $0.43^{\mathrm{x}}$ & $0.43^{\mathrm{x}}$ & 0.02 & 0.004 & 0.028 & 0.313 \\
\hline \multicolumn{11}{|l|}{ Pyrazines } \\
\hline Methyl pyrazine & 0.53 & 0.49 & 0.51 & 0.41 & 0.43 & 0.36 & 0.04 & 0.062 & 0.029 & 0.706 \\
\hline 2,5-Dimethyl pyrazine & 0.78 & 0.68 & 0.71 & 0.57 & 0.60 & 0.47 & 0.07 & 0.058 & 0.039 & 0.954 \\
\hline Trimethyl pyrazine & 0.53 & 0.48 & 0.51 & 0.44 & 0.47 & 0.40 & 0.04 & 0.213 & 0.028 & 0.915 \\
\hline 2-Ethyl-3,5-dimethyl pyrazine & 1.37 & 1.31 & 1.36 & 1.21 & 1.27 & 1.17 & 0.06 & 0.175 & 0.021 & 0.669 \\
\hline \multicolumn{11}{|l|}{ Esters } \\
\hline Acetic acid, methyl ester & 2.33 & 2.32 & 2.37 & 1.88 & 4.81 & 3.00 & 1.38 & 0.318 & 0.466 & 0.768 \\
\hline Butanoic acid, methyl ester & 1.89 & 1.26 & 1.99 & 1.33 & 3.65 & 1.34 & 0.72 & 0.324 & 0.036 & 0.364 \\
\hline Octanoic acid, methyl ester & $0.33^{\mathrm{y}}$ & $0.28^{\mathrm{y}}$ & $0.44^{x y}$ & $0.37^{x y}$ & $0.62^{\mathrm{x}}$ & $0.37^{\mathrm{x}}$ & 0.07 & 0.031 & 0.029 & 0.288 \\
\hline \multicolumn{11}{|l|}{ Alcohols } \\
\hline 1-Hexanol & 0.39 & 0.51 & 0.42 & 0.36 & 0.37 & 0.40 & 0.06 & 0.412 & 0.442 & 0.229 \\
\hline 1-Heptanol & 0.76 & 0.87 & 0.86 & 0.78 & 0.74 & 0.72 & 0.05 & 0.164 & 0.945 & 0.198 \\
\hline 1-Octen-3-ol & 1.03 & 1.78 & 0.87 & 0.85 & 0.73 & 0.71 & 0.27 & 0.093 & 0.168 & 0.127 \\
\hline
\end{tabular}

${ }^{\mathrm{a}-\mathrm{d}}$ Within a row, least squares means with different superscripts $\operatorname{differ}(P<0.05)$ due to diet $\times$ muscle interaction.

x,y Within a row, least squares means with different superscripts differ $(P<0.05)$ due to diet.

${ }^{1}$ Finishing diets: USUGrain = grain-finished; USUBFT $=$ birdsfoot trefoil-finished; USUGrass $=$ grass-finished.

${ }^{2} \mathrm{GM}=$ gluteus medius; $\mathrm{TB}=$ triceps brachii

${ }^{3}$ Pooled (largest) SE of least squares mean. 
Muscle had a profound influence on volatile flavor compounds, similar to past works (Legako et al., 2015; Hunt et al., 2016). Conversely, diet had a marginal impact on volatile flavor compounds. These results are in agreement with consumer liking of flavor, where diet did not impact flavor liking and muscle greatly impacted flavor liking. The majority of volatile compounds influenced by muscle type were products of the Maillard reaction. Specifically, 2-methyl butanal, 3-methyl butanal, and phenylacetaldehyde of the Strecker degradation pathway of the Maillard reaction were differentiated by muscle. These compounds develop through degradation of specific AA (alanine, isoleucine, and phenylalanine, respectively) and are generally regarded as positive flavor notes associated with cooking (Cerny, 2007). Additionally, methional, derived from methionine, was greater in GM compared with TB. Methional contains sulfur and is described has having a "meaty" aroma (Gasser and Grosch, 1990). Of further interest, 2,3-butanedione and multiple pyrazines of the Maillard reaction were greater in GM compared with TB. Recently, 2,3-butanedione was correlated with initial flavor impact, beef identity, bloody/serumy, fat-like, overall sweet, and umami assessed by descriptive panelists (Legako et al., 2016). Overall the 2 muscles differed greatly in nonlipid-derived volatile compounds, with the GM having greater quantities compared with the TB. Previously, the Maillard reaction has been demonstrated to be precursor compound (AA and reducing sugars) and $\mathrm{pH}$ dependent (Meynier and Mottram, 1995). In this study, the GM had a lower $\mathrm{pH}$ and greater AA-derived volatile compounds. Irrespective of the mechanism, muscle greatly impacted Maillard-derived volatile compound quantity in line with flavor liking. Meanwhile, far fewer volatile compounds of lipid origin were influenced by muscle. This result is in agreement with fatty acid data, which revealed relatively little variation between the 2 selected muscles. Overall, these results indicate that in this study, flavor liking and volatile flavor compounds of the selected muscles were being driven by nonlipid components. This conclusion is of consequence due to the long-standing belief that lipid constituents have the most prominent influence on flavor.

It does appear, however, that aroma liking in this study had a stronger association with diet and lipid components. As stated, volatile compounds were not greatly impacted by diet; however, lipid-derived carboxylic acids and carboxylic acid methyl esters were impacted by diet. Among these, butanoic acid, octanoic acid, and octanoic acid methyl ester were each determined to be lowest within USUGrain beef and greater in forage-finished beef. Carboxylic acids are associated with "grassy flavor" (Larick et al., 1987). As previously described, the aroma of USUGrain beef was more liked by consumers and USUGrain beef had comparatively lower $n-3$ fatty acids compared with the forage-finished beef. It may be speculated that the elevated levels of lipid-derived carboxylic compounds in forage-finished beef was due to greater lipid oxidation. Although these carboxylic compounds may not be direct results of $n-3$ fatty acid oxidation, it has previously been described that greater $n-3$ quantity may lead to greater initiation and propagation of lipid oxidation among adjacent fatty acids (Elmore et al., 1999).

From a dietary perspective, ratios of $n-6$ to $n-3$ less than 4.0 are recommended for health benefits (Simopoulos, 2004). Ratios of forage-finished beef (USUBFT and USUGrass) were all less than 4.0, whereas USUGrain beef ratios each exceeded 4.0. It is of note that muscle type did differ within the USUGrain treatment, with the GM having greater $n-6: n-3$ ratios compared with the TB. Although both ratios were above the recommended value, these results indicate that the GM and TB may be differentiated by having potentially more positive dietary fatty acid proportions.

This study offers insight into the perception of quality for beef producers, processors, and consumers. However, it should be noted that consumer data of this study was collected in only one region where the demographics are dominated by younger adults. Consumers determined the overall liking, tenderness, and quality rating of USUGrain GM and TB to be similar. However, forage-finished GM was perceived more frequently to be of premium quality, with greater tenderness and overall liking compared with the forage-finished TB. For beef that is grilled, grain-finished beef may provide more uniform quality throughout the entirety of the carcass than muscles from forage-finished beef.

\section{LITERATURE CITED}

American Meat Science Association (AMSA). 2015. Research guidelines for cookery, sensory evaluation, and instrumental tenderness measurement of fresh meat. AMSA, Champaign, IL.

AOAC. 1995. Official methods of analysis. 16th ed. AOAC Int., Arlington, VA.

AOAC. 2011. Official methods of analysis. 18th ed. AOAC Int., Arlington, VA.

Arab-Tehrany, E., M. Jacquot, C. Gaiani, M. Imran, S. Desobry, and M. Linder. 2012. Beneficial effects and oxidative stability of omega-3 long-chain polyunsaturated fatty acids. Trends Food Sci. Technol. 25:24-33. doi:10.1016/j.tifs.2011.12.002

Belew, J. B., J. C. Brooks, D. R. McKenna, and J. W. Savell. 2003. Warner-Bratzler shear evaluations of 40 bovine muscles. Meat Sci. 64:507-512. doi:10.1016/S0309-1740(02)00242-5

Carmack, C. F., C. L. Kastner, M. E. Dikeman, J. R. Schwenke, and C. M. García Zepeda. 1995. Sensory evaluation of beef-flavorintensity, tenderness, and juiciness among major muscles. Meat Sci. 39:143-147. doi:10.1016/0309-1740(95)80016-6

Cerny, C. 2007. Sensory evaluation of beef flavors In: L. M. L. Nollet, editor, Handbook of meat, poultry and seafood quality. Blackwell Publishing, Ames, IA. p. 311-326. 
Chail, A., J. F. Legako, L. R. Pitcher, T. C. Griggs, R. E. Ward, S. Martini, and J. W. MacAdam. 2016. Legume finishing provides beef with positive human dietary fatty acid ratios and consumer preference comparable with grain-finished beef. J. Anim. Sci. 94:2184-2197. doi:10.2527/jas.2015-0241

Corbin, C. H., T. G. O’Quinn, A. J. Garmyn, J. G. Legako, M. R. Hunt, T. T. Dinh, R. J. Rathmann, J. C. Brooks, and M. F. Miller. 2015. Sensory evaluation of tender beef strip loin steaks of varying marbling levels and quality treatments. Meat Sci. 100:24-31. doi:10.1016/j.meatsci.2014.09.009

Dryden, F., and J. Maechello. 1970. Influence of total lipid and fatty acid composition upon the palatability of three bovine muscles. J. Anim. Sci. 31:36-41. doi:10.2527/jas1970.31136x

Elmore, J. S., D. S. Mottram, M. Enser, and J. D. Wood. 1999. Effect of the polyunsaturated fatty acid composition of beef muscle on the profile of aroma volatiles. J. Agric. Food Chem. 47:1619-1625. doi:10.1021/j1980718m

Folch, J., M. Lees, and G. Sloane-Stanley. 1957. A simple method for the isolation and purification of total lipids from animal tissues. J. Biol. Chem. 226:497-509.

Gasser, U., and W. Grosch. 1990. Primary odorants of chicken broth Z. Lebensm. Unters. Forsch. 190:3-8. doi:10.1007/BF01188254

Hunt, M. R., A. J. Garmyn, T. G. O’Quinn, C. H. Corbin, J. F. Legako, R. J. Rathmann, J. C. Brooks, and M. F. Miller. 2014. Consumer assessment of beef palatability from four beef muscles from USDA Choice and Select graded carcasses. Meat Sci. 98:1-8. doi:10.1016/j.meatsci.2014.04.004

Hunt, M. R., J. F. Legako, T. T. Dinh, A. J. Garmyn, T. G. O'Quinn, C. H. Corbin, R. J. Rathmann, J. C. Brooks, and M. F. Miller. 2016. Assessment of volatile compounds, neutral and polar lipid fatty acids of four beef muscles from USDA Choice and Select graded carcasses and their relationships with consumer palatability scores and intramuscular fat content. Meat Sci. 116:91-101. doi:10.1016/j.meatsci.2016.02.010

John, L., D. Cornforth, C. E. Carpenter, O. Sorheim, B. C. Pettee, and D. R. Whittier. 2004. Comparison of color and thiobarbituric acid values of cooked hamburger patties after storage of fresh beef chubs in modified atmospheres. J. Food Sci. 69:C608-C614. doi:10.1111/j.1365-2621.2004.tb09908.x

King, D. A., T. L. Wheeler, S. D. Shackelford, and M. Koohmaraie. 2009. Comparison of palatability characteristics of beef gluteus medius and triceps brachii muscles. J. Anim. Sci. 87:275-284. doi:10.2527/jas.2007-0809

Larick, D. K., H. B. Hedrick, M. E. Bailey, J. E. Williams, D. L. Hancock, G. B. Garner, and R. E. Morrow. 1987. Flavor constituents of beef as influenced by forage- and grain-feeding. J. Food Sci. 52:245-251. doi:10.1111/j.1365-2621.1987.tb06585.x

Legako, J. F., J. C. Brooks, T. G. O’Quinn, T. D. Hagan, R. Polkinghorne, L. J. Farmer, and M. F. Miller. 2015. Consumer palatability scores and volatile beef flavor compounds of five USDA quality grades and four muscles. Meat Sci. 100:291-300. doi:10.1016/j.meatsci.2014.10.026

Legako, J. F., T. T. Dinh, M. F. Miller, K. Adhikari, and J. C. Brooks. 2016. Consumer palatability scores, sensory descriptive attributes, and volatile compounds of grilled beef steaks from three USDA quality grades. Meat Sci. 112:77-85. doi:10.1016/j.meatsci.2015.10.018

Lucherk, L. W., T. G. O’Quinn, J. F. Legako, R. J. Rathmann, J. C. Brooks, and M. F. Miller. 2016. Consumer and trained panel evaluation of beef strip steaks of varying marbling and enhancement levels cooked to three degrees of doneness. Meat Sci. 122:145-154. doi:10.1016/j.meatsci.2016.08.005
Martin, J. N., J. C. Brooks, L. D. Thompson, J. W. Savell, K. B. Harris, L. L. May, A. N. Haneklaus, J. L. Schutz, K. E. Belk, T. Engle, D. R. Woener, J. F. Legako, A. M. Luna, L. W. Douglas, S. E. Douglas, J. Howe, M. Duvall, K. Y. Patterson, and J. L. Leheska. 2013. Nutrient database improvement project: The influence of U.S.D.A. quality and yield grade on the separable components and proximate composition of raw and cooked retail cuts from the beef rib and plate. Meat Sci. 95(3):486-494. doi:10.1016/j. meatsci.2013.05.031

Maughan, C., R. Tansawat, D. Cornforth, R. Ward, and S. Martini. 2012. Development of a beef flavor lexicon and its application to compare the flavor profile and consumer acceptance of rib steaks from grass- or grain-fed cattle. Meat Sci. 90:116-121. doi:10.1016/j.meatsci.2011.06.006

Mc Keith, F., R. Miles, P. Bechtel, and T. Carr. 1985. Chemical and sensory properties of thirteen major beef muscles. J. Food Sci. 50:869-872. doi:10.1111/j.1365-2621.1985.tb12968.x

Meisinger, J. L., J. M. James, and C. R. Calkins. 2006. Flavor relationships among muscles from the beef chuck and round. J. Anim. Sci. 84:2826-2833. doi:10.2527/jas.2006-028

Melton, S. L. 1990. Effects of feeds on flavor of red meat: A review. J. Anim. Sci. 68:4421-4435. doi:10.2527/1990.68124421x

Meynier, A., and D. S. Mottram. 1995. The effect of $\mathrm{pH}$ on the formation of volatile compounds in meat-related model systems. Food Chem. 52:361-366. doi:10.1016/0308-8146(95)93282-V

Moser, C., and K. Herman. 2011. Method for the rapid determination of protein in meats using the CEM Sprint ${ }^{\mathrm{TM}}$ protein analyzer: Collaborative study. J. AOAC Int. 94:1555-1561. doi:10.5740/ jaoacint.CS2011_04

North American Meat Processors Association (NAMPA). 2010. The meat buyer's guide. 6th ed. North American Meat Processors Association, Reston VA.

O'Fallon, J. V., J. R. Busboom, M. L. Nelson, and C. T. Gaskins. 2007. A direct method for fatty acid methyl ester synthesis: Application to wet meat tissues, oils, and feedstuffs. J. Anim. Sci. 85:15111521. doi:10.2527/jas.2006-491

O'Quinn, T. G., J. C. Brooks, R. J. Polkinghorne, A. J. Garmyn, B. J. Johnson, J. D. Starkey, R. J. Rathmann, and M. F. Miller. 2012. Consumer assessment of beef strip loin steaks of varying fat levels. J. Anim. Sci. 90:626-634. doi:10.2527/jas.2011-4282

O'Quinn, T. G., D. R. Woerner, T. E. Engle, P. L. Chapman, J. F. Legako, J. C. Brooks, K. E. Belk, and J. D. Tatum. 2016. Identifying consumer preferences for specific beef flavor characteristics in relation to cattle production and postmortem processing parameters. Meat Sci. 112:90-102. doi:10.1016/j.meatsci.2015.11.001

Philip, C. M. 2011. Differentiation of beef flavor across muscles and quality grades. Texas A\&M University, College Station, TX.

Rhee, M.-S., T. Wheeler, S. Shackelford, and M. Koohmaraie. 2004. Variation in palatability and biochemical traits within and among eleven beef muscles. J. Anim. Sci. 82:534-550. doi: $10.2527 / 2004.822534 \mathrm{x}$

Romeu-Nadal, M., J. Chavez-Servin, A. Castellote, M. Rivero, and M. Lopez-Sabater. 2007. Oxidation stability of the lipid fraction in milk powder formulas. Food Chem. 100:756-763. doi:10.1016/j. foodchem.2005.10.037

Simopoulos, A. P. 2004. Omega-6/omega-3 essential fatty acid ratio and chronic diseases. Food Rev. Int. 20:77-90. doi:10.1081/FRI120028831

Stetzer, A. J., K. Cadwallader, T. K. Singh, F. K. Mc Keith, and M. S. Brewer. 2008. Effect of enhancement and ageing on flavor and volatile compounds in various beef muscles. Meat Sci. 79:13-19. doi:10.1016/j.meatsci.2007.07.025

Tansawat, R., C. A. J. Maughan, R. E. Ward, S. Martini, and D. P. Cornforth. 2013. Chemical characterisation of pasture- and grainfed beef related to meat quality and flavour attributes. Int. J. Food Sci. Technol. 48:484 495. doi:10.1111/j.13652621.2012.03209.x 